\title{
Three-dimensional characterisation of particle size and shape for ballast
}

\author{
Y. SUN*, B. INDRARATNA* ${ }^{*}$ and S. NIMBALKAR*
}

\begin{abstract}
The size and shape of particles influence how effectively coarse angular aggregates of ballast interact. The aim of this study was to improve the characterisation of ballast particles using a threedimensional (3D) imaging method. Various size and shape indices, such as elongation ratio, sphericity and roundness, were determined from the scanned 3D images. A modified index called 'ellipsoidness' was proposed to capture adequately the shape of the 3D particles. Variation of these indices with particle size was studied. Comparison of the 3D true sphericity and the corresponding two-dimensional sphericity indicated that the latter would underestimate sphericity. A modified approach for transforming particle size distribution to constriction size distribution is proposed by capturing the size and shape effects of particles.
\end{abstract}

KEYWORDS: gravels; laboratory tests; particle-scale behaviour

ICE Publishing: all rights reserved

\section{NOTATION}

$\begin{array}{ll}D_{\mathrm{c}} & \text { constriction size } \\ D_{\mathrm{cD}} & \text { densest constriction size } \\ D_{\mathrm{cL}} & \text { loosest constriction size } \\ d_{i} & \text { discretised diameter } \\ d_{n} & \text { equivalent diameter } \\ E & \text { three-dimensional ellipsoidness } \\ E_{2 \mathrm{D}} & \text { two-dimensional ellipseness } \\ I & \text { medium axis length } \\ L & \text { major axis length } \\ m & \text { real particle mass } \\ P_{\mathrm{c}} & \text { value of percent finer } \\ P_{\mathrm{e}} & \text { perimeter of equivalent area ellipse } \\ P_{\mathrm{M} i} & \text { mass probabilities of occurrence in corresponding } \\ P_{\mathrm{N} i} & \text { discretised diameter } \\ P_{\mathrm{o}} & \text { number probabilities of occurrence in correspond- } \\ P_{\mathrm{SA} i} & \text { ing discretised diameter } \\ R & \text { perimeter of the projection of a particle } \\ R_{\mathrm{d}} & \text { surface area probabilities of occurrence in corre- } \\ S & \text { sponding discretised diameter } \\ S_{\mathrm{e}} & \text { roundness } \\ S_{\mathrm{O}} & \text { relative density } \\ V & \text { minor axis length } \\ \psi & \text { surface area of equivalent volume ellipsoid } \\ \psi_{1} & \text { surface area of the scanned particle } \\ & \text { volume of the ellipsoid } \\ \text { true sphericity }\end{array}$

\section{INTRODUCTION}

The size and shape of aggregates have long been recognised as the two major factors that significantly affect the performance of ballast, but investigations into these effects are limited (Thom \& Brown, 1988; Le Pen et al., 2013;

Manuscript received 9 May 2014; first decision 12 June 2014; accepted 16 July 2014.

Published online at www.geotechniqueletters.com on 19 August 2014.

${ }^{*}$ Centre for Geomechanics and Railway Engineering, University of Wollongong, Wollongong, NSW, Australia

$\dagger$ †RC Centre of Excellence for Geotechnical Science and Engineering, University of Wollongong, Wollongong, NSW, Australia
Moaveni et al., 2014). Previous studies on sandy soils revealed that particle shape and size would have a significant influence on the physical and mechanical properties of sandy soils (Cho et al., 2006; Cavarretta et al., 2010; Shin \& Santamarina, 2012; Altuhafi et al., 2013). Higher angularity and uniform grading promote breakage and reduce the strength of aggregates until a fractal particle size distribution (PSD) is reached (Einav, 2007). Cunningham et al. (2013) reported varied performance of crushed stone aggregates due to the use of different PSDs, which could also be attributed to varying particle shapes. Past studies have reported that the angularity of crushed rock aggregates usually increases with an increase in size (Cunningham et al., 2013; Le Pen et al., 2013). Unlike sandy soils, coarse angular ballast $(d>$ $9.5 \mathrm{~mm}$ ) breaks even under low confining pressure due to high internal stress concentrations, as has been demonstrated in large-scale triaxial tests (Lackenby et al., 2007). Apart from the larger particle size, particle irregularity can be regarded as a possible reason for this.

Particle size distribution analysis is one of the main methods used to determine the size of aggregates (Standards Australia, 1999). Sieving is a bulk approximation of particle size and cannot quantify the actual shape of particles, whereas an image-based analysis is more objective (e.g. Lee et al., 2007; Muszynski \& Vitton, 2012; Altuhafi et al., 2013). However, many studies in the literature (e.g. Cho et al., 2006; Rousé et al., 2008; Altuhafi et al., 2013; Le Pen et al., 2013) are based on two-dimensional (2D) or pseudo threedimensional (3D) scanning, which cannot provide comprehensive information about the form of individual particles. Clear differences between the 2D and 3D shape measurements were observed by Fonseca et al. (2012). As will be shown later in this paper, 2D analysis can underestimate the true sphericity of particles.

The aim of this work was to perform comprehensive 3D assessments of particle size and shape utilising a 3D laser scanner. Particle size and shape indices such as the flatness ratio, the elongation ratio and true sphericity are presented. In particular, a modified 3D ellipsoidness index is proposed instead of conventional sphericity and roundness index. The size dependence of these particle shape indices is evaluated. The role of the constriction size distribution 
(CSD) in lieu of the PSD is also discussed, based on the surface area and the number of particles. Here, constriction means the largest void that can fit within the tangent particles and the size of a constriction depends on the compacted density.

\section{EXPERIMENTAL INVESTIGATION}

The ballast used in this study was a latite basalt, which is a dark-coloured volcanic rock containing the primary minerals feldspar, plagioclase and augite (Lackenby et al., 2007). Using the standard sieving method (ASTM, 2006), particles were divided into seven size intervals: $13 \cdot 2$ $19.0 \mathrm{~mm} ; 19 \cdot 0-26.5 \mathrm{~mm} ; 26.5-31.5 \mathrm{~mm} ; 31.5-37.5 \mathrm{~mm}$; $37 \cdot 5-40 \cdot 0 \mathrm{~mm} ; 40 \cdot 0-45 \cdot 0 \mathrm{~mm} ; 45 \cdot 0-53 \cdot 0 \mathrm{~mm}$. Ballast particles were selected based on visual inspection; those with surface cracks or aggregates with extremely flat or elongated shapes were excluded to avoid inaccuracy. Adopting the approach used by Cho et al. (2006), 30 particles were carefully selected from each sieve. These particles were painted white and then marked with small dots to facilitate different alignments during the scanning process (Fig. 1).

A non-contact 3D laser scanner (VIVID 910) with an accuracy of $0.22 \mathrm{~mm}$ horizontally, $0.16 \mathrm{~mm}$ vertically and $0.10 \mathrm{~mm}$ longitudinally was used, adopting the triangulation light block method. The sample was first placed on a black pedestal and then scanned by the laser light, the plane of which was rotated by a precise galvanometer. Each reflected scan line was captured by a CCD (charge coupled device) camera. The surface contour was then derived and converted into a lattice of over 300000 vertices, thus forming a polygonal mesh. Noise and small holes on the merged model were then corrected using the image analysis software Geomagic Qualify 12 (version 15.0). Figure 1 shows a representative ballast particle and its corresponding scanned 3D image. The software used divides the surface mesh of the scanned ballast particle into triangular sub-surfaces called polyfaces. The total surface area is then obtained by the sum of all the polyfaces and the total volume can be computed by the sum of the sub-volumes of the tetrahedral mesh. As shown in Fig. 2, an excellent linear correlation $\left(R^{2}=0.99\right)$ between the real particle mass $m$ and its corresponding scanned volume $V$ was observed. In addition, the specific gravity of the particle, which equals the gradient of the fitting line, was precisely $2 \cdot 66$.

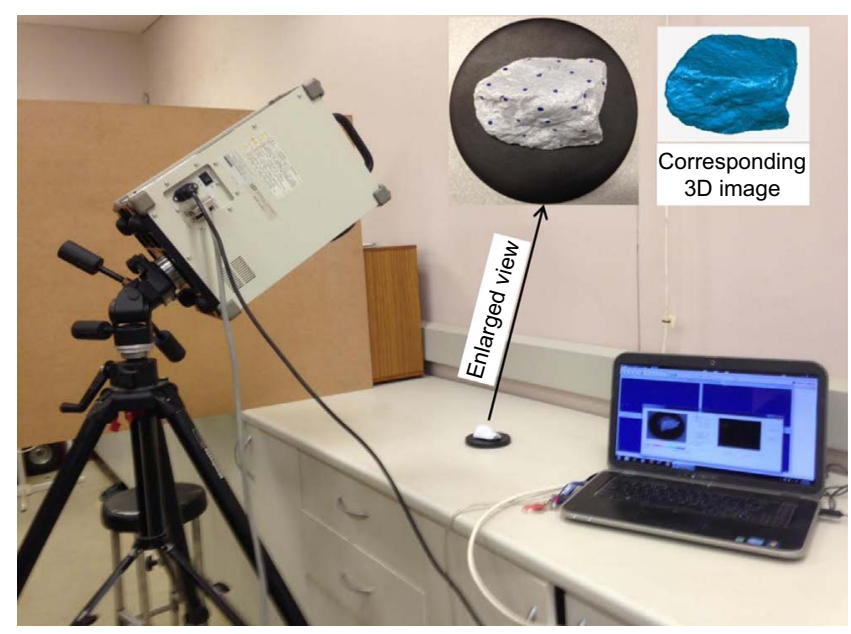

Fig. 1. Test setup

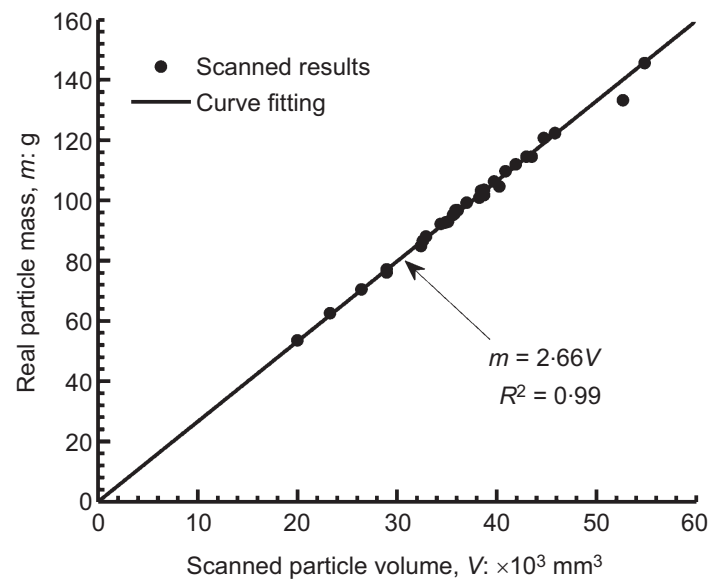

Fig. 2. Relationship between real mass of ballast and its corresponding scanned volume

\section{MEASUREMENT OF SIZE AND SHAPE INDICES}

The most frequently used particle size quantifications are the lengths of three representative axes - the major axis length $L$, medium axis length $I$ and minor axis length $S$, where the medium axis length $I$ is usually correlated to the sieve size. These lengths can be easily measured by calculating the lengths of the sides of a rectangular solid box bounding the particle, as suggested by Fernlund (1998). After that, particle shape parameters such as the elongation ratio $I / L$ and flatness ratio $S / I$ can be defined from the available axis lengths.

Apart from these particle lengths and their derivatives, various $2 \mathrm{D}$ and $3 \mathrm{D}$ parameters are conventionally used in practice (e.g. 3D true sphericity $\psi$ and 2D roundness $R$ (Wadell, 1935), 2D sphericity $\psi_{1}$ (Krumbein, 1941) and 2D ellipseness $E_{2 \mathrm{D}}$ introduced by Le Pen et al. (2013), as shown in Table 1). However, estimating the roundness depends on proper assessment of the curved corners of the particle. This is subjective because the outline of an angular particle appears differently at different viewing scales. However, the sensitivity of the outline to the scale value was not compared in the current study. The scale value used in this research was $0 \cdot 1 \mathrm{~mm}$. The other shape parameters do not require determination of the curved corner and are thus unaffected by this limitation. 3D analysis is expected to provide a more realistic match to the actual shape of a particle. To facilitate the $3 \mathrm{D}$ analysis, a modified measure called 'ellipsoidness' $E$ is proposed here. Ellipsoidness is defined as the ratio between the surface area $S_{\mathrm{e}}$ of the equivalent volume $V$ ellipsoid (with major radius $a=L / 2$ and minor radii $b$ and $c$ ) and the particle surface area $S_{\mathrm{o}}$. For simplicity, $a>b=c$ is assumed. Once the representative particle lengths and volume are known, the minor radius $b$ (or $c$ ) as well as $S_{\mathrm{e}}$ can be obtained from

$$
\begin{aligned}
& b=\left(\frac{3 V}{2 \pi L}\right)^{1 / 2} \\
& S_{\mathrm{e}}=4 \pi\left(b^{2}+a^{2} \frac{\arccos (b / a)}{\tan [\arccos (b / a)]}\right)
\end{aligned}
$$

It was noted that $S_{\mathrm{o}}$ would decrease with decreasing angularity of a ballast particle for the same value of the actual volume $V . S_{\mathrm{o}}$ would approach $S_{\mathrm{e}}$ with $E$ approaching 1 when the surface of the particle becomes increasingly round. 
Table 1. Particle shape indices and constriction sizes

\begin{tabular}{|c|c|}
\hline Method & Description \\
\hline & $\begin{array}{l}\psi=s_{n} / S_{\mathrm{o}}: s_{n} \text { is the surface area of a sphere having the same volume as the scanned particle and } S_{\mathrm{o}} \text { is the ac } \\
\text { surface area }\end{array}$ \\
\hline $\begin{array}{l}\text { 2D sphericity } \psi_{1} \\
\text { Krumbein, 1941) }\end{array}$ & $\psi_{1}=d_{n} / \mathrm{L}: d_{n}$ is the equivalent diameter of a sphere having the same value of particle volume $V$ \\
\hline $\begin{array}{l}\text { Roundness } R \\
\text { (Wadell, 1935) }\end{array}$ & $R=\frac{\sum r_{i} / n}{r_{\max }}: r_{i}$ and $r_{\max }$ are the radius of the corner and the maximum inscribed circle, respectively; $n$ is \\
\hline & $\begin{array}{l}\text { the total number of corners in the particle outline. Note } R \text { measures the projection of a particle on the } \\
\text { plane perpendicular to its minor axis } S\end{array}$ \\
\hline $\begin{array}{l}\text { Ellipseness } E_{2 \mathrm{D}} \\
\text { (Le Pen et al., } \\
\text { 2013) }\end{array}$ & $\begin{array}{l}E_{2 \mathrm{D}}=P_{\mathrm{e}} / P_{\mathrm{o}}: P_{\mathrm{e}} \text { is the perimeter of an ellipse having the same area as the projection of a particle and } P_{\mathrm{o}} \text { is the actual } \\
\text { perimeter of the projection }\end{array}$ \\
\hline $\begin{array}{l}D_{\mathrm{cD}}(\text { Humes, } \\
1996)\end{array}$ & $\begin{array}{l}\left(\frac{2}{D_{1}}\right)^{2}+\left(\frac{2}{D_{2}}\right)^{2}+\left(\frac{2}{D_{3}}\right)^{2}+\left(\frac{2}{D_{\mathrm{cD}}}\right)^{2}=0 \cdot 5\left(\frac{2}{D_{1}}+\frac{2}{D_{2}}+\frac{2}{D_{3}}+\frac{2}{D_{\mathrm{cD}}}\right)^{2}: D_{1}, D_{2} \text { and } D_{3} \text { are diameters of three } \\
\text { constituting particles }\end{array}$ \\
\hline $\begin{array}{l}D_{\mathrm{cL}} \text { (Silveira et al., } \\
1975)\end{array}$ & $D_{\mathrm{cL}}=\left(4 S_{\mathrm{c}, \max } / \pi\right)^{1 / 2}: S_{\mathrm{c}, \max }$ is the maximum constriction space among four constituting particles \\
\hline
\end{tabular}

\section{CONSTRICTION SIZE DISTRIBUTION AND PARTICLE SIZE DISTRIBUTION}

Constriction size distribution defines the size distribution of the void network in granular soils (Silveira et al., 1975; Indraratna et al., 2007). Migration of sub-ballast fines can be controlled by adopting an appropriate ballast CSD. The CSD can also be applied to control PSD and relative density $R_{\mathrm{d}}$ during mechanised maintenance of railroad ballast, which involves blowing smaller-sized gravel between the ballast and the base of the sleeper (Anderson \& Fair, 2008). The CSD is usually determined based on the PSD by number or surface area, which can be transformed from the PSD by mass according to

$$
\begin{aligned}
& P_{\mathrm{N} i}=\frac{P_{\mathrm{M} i} / d_{i}^{3}}{\sum_{i=1}^{n} P_{\mathrm{M} i} / d_{i}^{3}} \\
& P_{\mathrm{SA} i}=\frac{P_{\mathrm{M} i} / d_{i}}{\sum_{i=1}^{n} P_{\mathrm{M} i} / d_{i}}
\end{aligned}
$$

where $P_{\mathrm{M} i}, P_{\mathrm{N} i}$ and $P_{\mathrm{SA} i}$ are respectively the mass, number and surface area probabilities of occurrence in a corresponding discretised diameter $d_{i}$. Note that the discretised diameter $d_{i}$ is usually treated as the geometrical average of two neighbouring sieves. Considering the effect of relative density $R_{\mathrm{d}}$ on the CSD, Locke et al. (2001) developed the following equation for relating the constriction size $D_{\mathrm{c}}$ with a given value of the percent finer $P_{\mathrm{c}}$ by extending the initial work of Humes (1996)

$$
D_{\mathrm{c}}=D_{\mathrm{cD}}+P_{\mathrm{c}}\left(1-R_{\mathrm{d}}\right)\left(D_{\mathrm{cL}}-D_{\mathrm{cD}}\right)
$$

where the densest constriction size $D_{\mathrm{cD}}$ (Table 1) is the diameter of the largest circle that can fit within three tangent particles. The loosest constriction size $D_{\mathrm{cL}}$ (Table 1) corresponds to the equivalent diameter of the maximum constriction space among four constituting particles, as defined by Silveira et al. (1975). Trani \& Indraratna (2010) suggested the use of a PSD based on particle surface area instead of the mass-based PSD to determine the CSD of granular soils. A good prediction was observed. It seems that the use of a surface-area-based PSD can automatically weaken the particle shape and size effect on the calculation of the CSD. However, to completely eliminate the effect of particle size and shape, an improved prediction was suggested by substituting the geometrical average in equations (3a) and (3b) by the equivalent diameter $d_{n}$ of each sieve interval

$$
\begin{gathered}
P_{\mathrm{N} i}=\frac{P_{\mathrm{M} i} / d_{n i}^{3}}{\sum_{i=1}^{n} P_{\mathrm{M} i} / d_{n i}^{3}} \\
P_{\mathrm{SA} i}=\frac{P_{\mathrm{M} i} / d_{n i}}{\sum_{i=1}^{n} P_{\mathrm{M} i} / d_{n i}}
\end{gathered}
$$

where $d_{n i}$ is the average equivalent diameter of each sieve interval. $d_{n}$ is slightly larger than the geometrical average $d_{i}$ and should approach $d_{i}$ with increasing particle regularity. In this study, two different PSDs were selected by grouping a certain number of particles in each size range and then the corresponding CSDs were determined following this modified approach.

\section{RESULTS AND DISCUSSION}

The distributions of various size and shape indices of individual particles from different sieve intervals are plotted in Figs 3-8. To show the overall trend of evolution, the best-fitted straight lines are also drawn along with the average values of particle shape indices. Distributions of

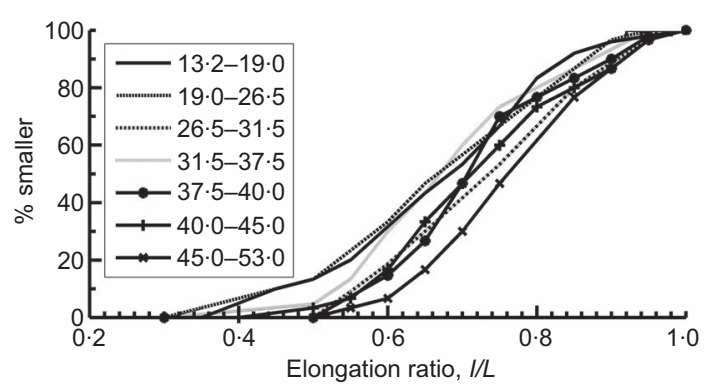

(a)

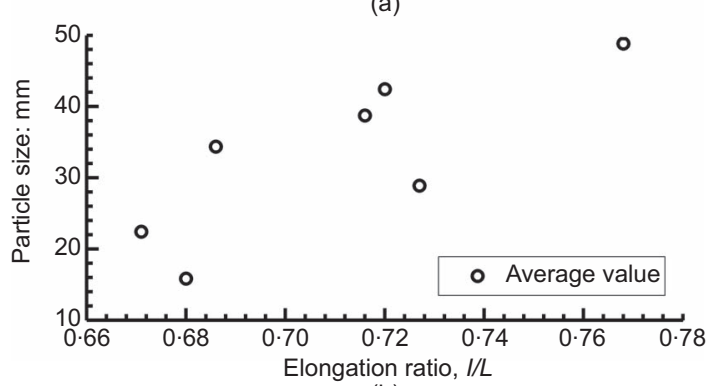

(b)

Fig. 3. (a) Distribution of elongation ratio I/L. (b) Evolution of its average value with particle size 


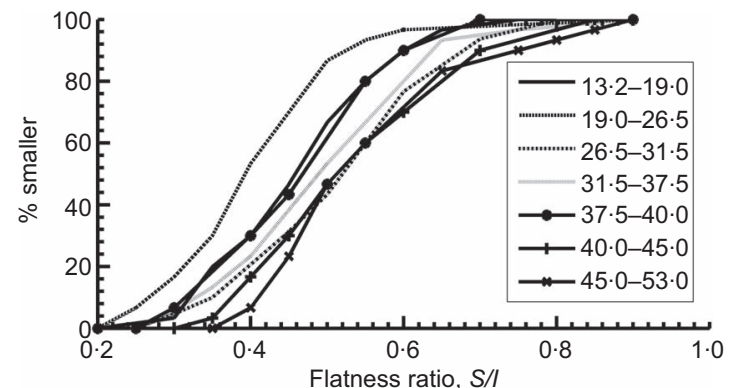

(a)

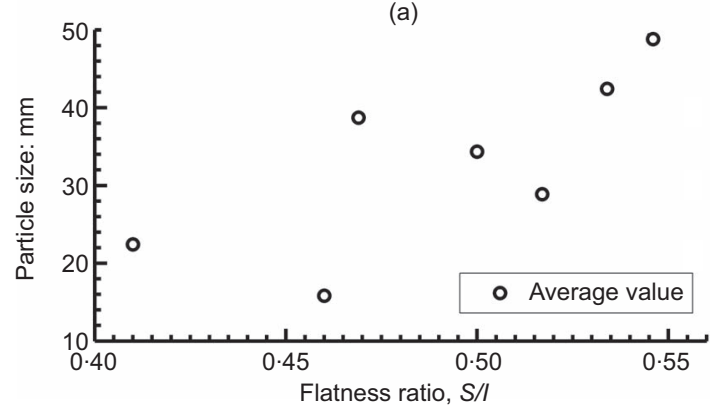

(b)

Fig. 4. (a) Distribution of flatness ratio S/I. (b) Evolution of its average value with particle size

the elongation ratio and flatness ratio are plotted in Figs 3(a) and 4(a), respectively. The results indicate that most particles were slightly elongated and moderately flat, while only a small fraction of ballast remained moderately elongated and very flat according to the modified Zingg classification (Blott \& Pye, 2008). This differs from the results reported by Le Pen et al. (2013) where most of the ballast particles were found to be slightly flat and elongated. This discrepancy could be attributed to the different stone crushing techniques in quarries. Average values of the elongation ratios from each sieve interval are plotted in Figs 3(b) and 4(b), from which one can tell that both the elongation ratio and flatness ratio increase with increasing particle size, indicating that more elongated and flat shapes

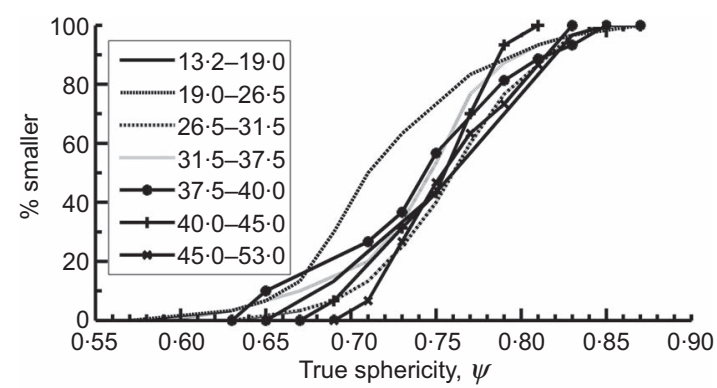

(a)

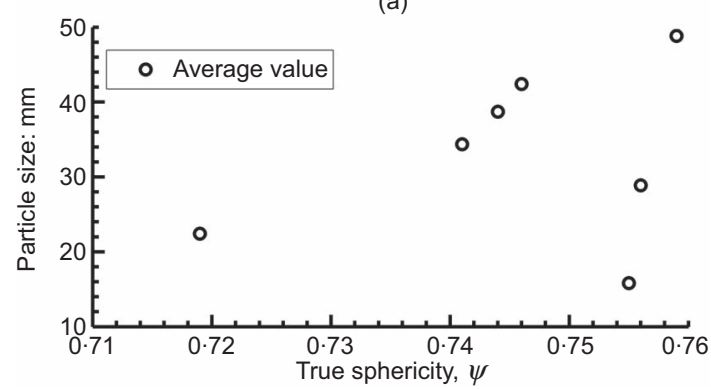

(b)

Fig. 5. (a) Distribution of true sphericity $\psi$. (b) Evolution of its average value with particle size

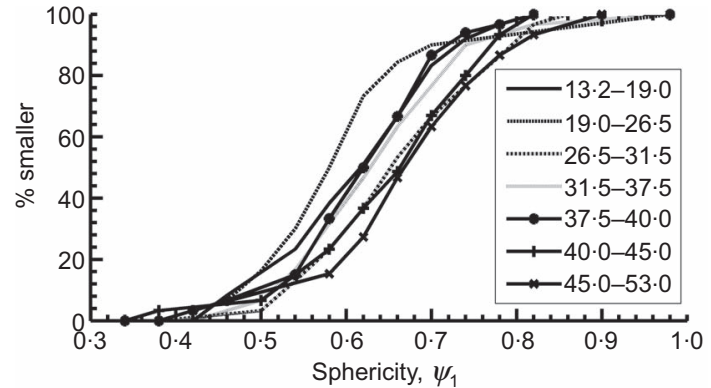

(a)

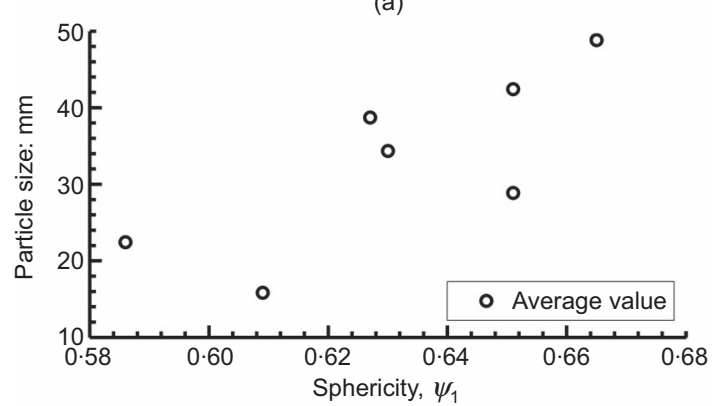

(b)

Fig. 6. (a) Distribution of 2D sphericity $\psi_{1}$. (b) Evolution of its average value with particle size

should be observed in smaller particles. This is indeed in accordance with the work of Altuhafi \& Coop (2011) who found a lower aspect (elongation) ratio in smaller particles.

Figures 5 and 6 show plots of true (3D) sphericity $\psi$ and corresponding 2D sphericity $\psi_{1}$, respectively. As illustrated in Fig. 5(a), true sphericity $\psi$ was mainly in the range 0.7 $0 \cdot 8$, while $2 \mathrm{D}$ sphericity $\psi_{1}$ (Fig. 6(a)) mainly ranged between 0.5 and 0.7 . It is obvious that the $2 \mathrm{D}$ analysis underestimated the true sphericity of the scanned particles. A similar observation was reported by Fonseca et al. (2012) who used CT images to study the particle shape of sands. It should be noted that $3 \mathrm{D}$ sphericity and $2 \mathrm{D}$ sphericity are different considering their geometrical definitions. The 2D sphericity actually measures the projection of a particle

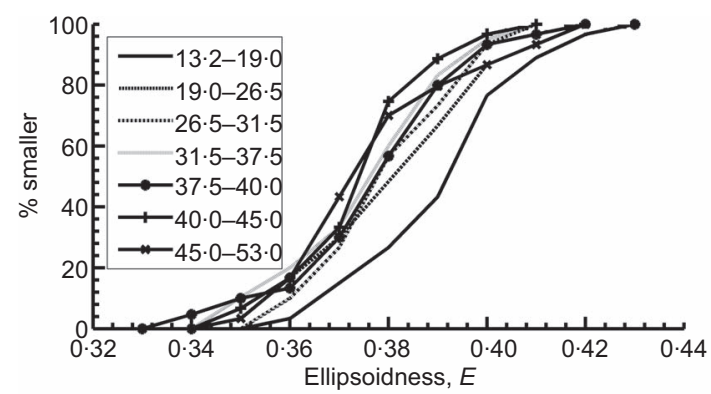

(a)

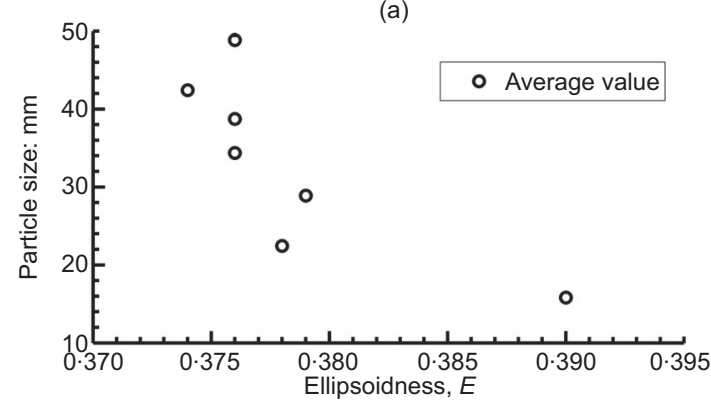

(b)

Fig. 7. (a) Distribution of ellipsoidness E. (b) Evolution of its average value with particle size 


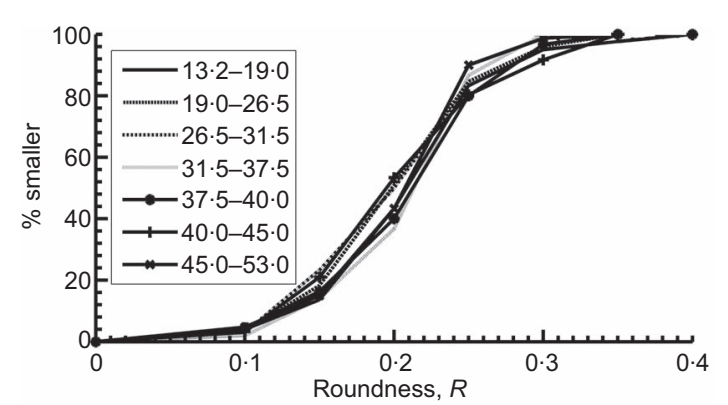

(a)

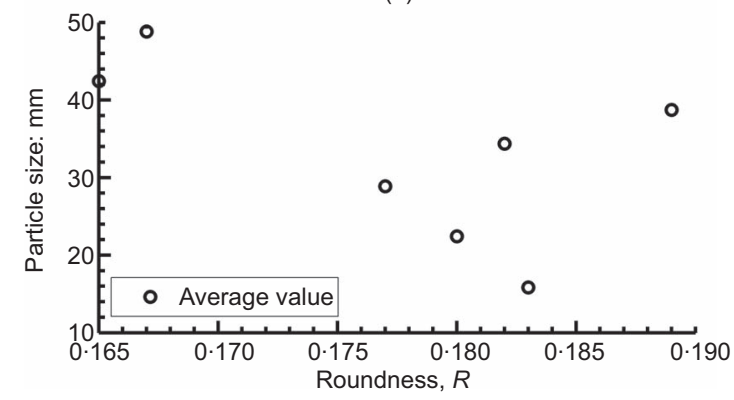

(b)

Fig. 8. (a) Distribution of roundness R. (b) Evolution of its average value with particle size

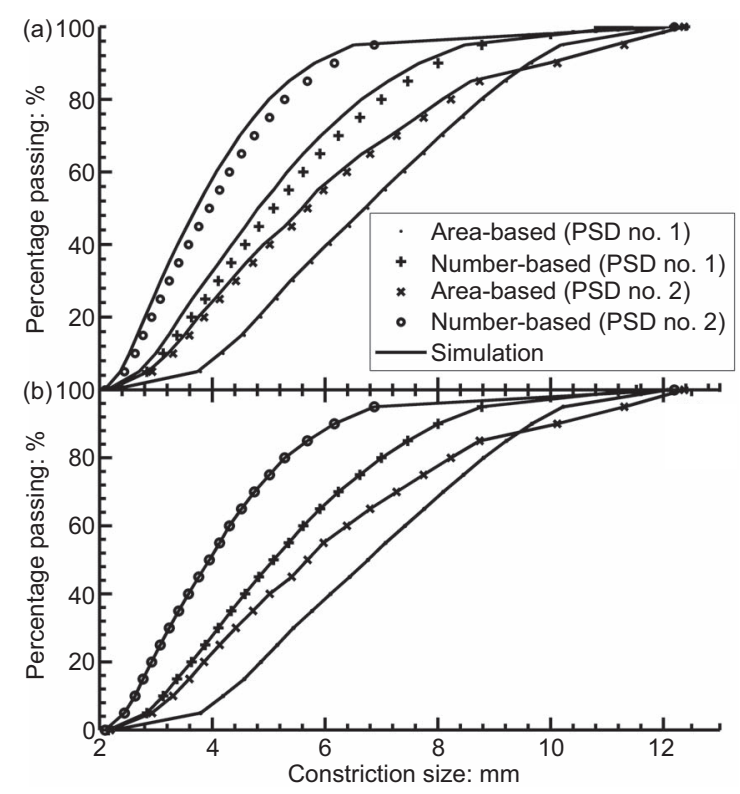

Fig. 9. Predictions of CSDs based on (a) geometrical average (Trani \& Indraratna, 2010) and (b) equivalent diameter while the 3D sphericity measures the real particle shape. If the particle was near spherical, both $3 \mathrm{D}$ and $2 \mathrm{D}$ values would approach unity. However, natural particles are mostly irregular, thus different values of $2 \mathrm{D}$ sphericity can be observed from different particle projections. Therefore, a $3 \mathrm{D}$ investigation is necessary to obtain an accurate evaluation of particle shape. Moreover, both the average values of true sphericity (Fig. 5(b)) and 2D sphericity (Fig. 6(b)) increase with increasing particle size.

The distribution of ellipsoidness $E$ (Fig. 7(a)) shows a greater variation among different sieve intervals than the distribution of roundness $R$ (Fig. 8(a)). The average values of both $E$ (Fig. 7(b)) and $R$ (Fig. 8(b)) exhibit a slight decrease with increasing particle size, which implies that greater angularity should be observed among larger particles. Even though the particle surface irregularity of each sieve interval may only show a little variation, it would still have a significant influence on the mechanical response of granular soils (O'Sullivan et al., 2002).

The CSD is usually predicted based on the geometrical average of particle size. Figure 9(a) presents the CSD predictions of the corresponding PSDs in Table 2 by Trani \& Indraratna (2010) who used equations (3a) and (3b). The figure shows that the method based on geometrical average over-predicted the CSDs predicted by number in contrast to surface area. This means that predictions based on a traditional transforming method can still overestimate the fraction of larger particles even if a mass-based PSD is not used. This is possibly because equations (3a) and (3b) intrinsically treat the particle as a sphere, when in fact natural particles are mainly of irregular form. Very accurate predictions of CSDs based on the equivalent diameter using equations (5a) and (5b) can be observed in Fig. 9(b). The use of the equivalent diameter carefully considers the shape effect of the particles of each sieve interval. Thus, the effect of the size and shape of individual particles on the calculations of particle number and particle surface area have been safely addressed.

\section{CONCLUSIONS}

The mechanical behaviour of railway ballast is sensitive to variations in shape apart from the PSD. However, ballast shape and size have only been qualitatively characterised in previous works. This study presented a quantitative assessment of size and shape of ballast using a 3D laser scanning method through the analysis of over 200 particles. A new shape index, 'ellipsoidness', was introduced as a better representative index of particle shape. It was observed that particle shape was also dependent on size: the elongation ratio, flatness ratio and the sphericity of particles increased with an increase in particle size, whereas the roundness and ellipsoidness decreased slightly as particle size increased. Therefore, it is expected that a larger particle assemblage such as railroad ballast would

Table 2. Randomly selected PSDs used for the calculation of CSDs

\begin{tabular}{l|l|c|c|c|c|c|c|c}
\hline & \multirow{2}{*}{} & Grading method & \multicolumn{7}{c}{ Size interval: $\mathrm{mm}$} \\
\cline { 3 - 9 } & & $13 \cdot 2-19 \cdot 0$ & $19 \cdot 0-26 \cdot 5$ & $26 \cdot 5-31 \cdot 5$ & $31 \cdot 5-37 \cdot 5$ & $37 \cdot 5-40 \cdot 0$ & $40 \cdot 0-45 \cdot 0$ & $45 \cdot 0-53 \cdot 0$ \\
\hline PSD no. 1 & Mass-based & $0 \cdot 017$ & $0 \cdot 033$ & $0 \cdot 077$ & $0 \cdot 135$ & $0 \cdot 180$ & $0 \cdot 240$ & $0 \cdot 318$ \\
PSD no. 1 & Area-based & $0 \cdot 036$ & $0 \cdot 060$ & $0 \cdot 101$ & $0 \cdot 148$ & $0 \cdot 180$ & $0 \cdot 218$ & $0 \cdot 257$ \\
PSD no. 1 & Number-based & $0 \cdot 143$ & $0 \cdot 143$ & $0 \cdot 143$ & $0 \cdot 142$ & $0 \cdot 143$ & $0 \cdot 143$ & $0 \cdot 143$ \\
PSD no. 2 & Mass-based & $0 \cdot 046$ & $0 \cdot 090$ & 0 & 0 & 0 & 0 & $0 \cdot 864$ \\
PSD no. 2 & Area-based & $0 \cdot 103$ & $0 \cdot 169$ & 0 & 0 & 0 & 0 & $0 \cdot 728$ \\
PSD no. 2 & Number-based & $0 \cdot 333$ & $0 \cdot 334$ & 0 & 0 & 0 & 0 & $0 \cdot 333$ \\
\hline
\end{tabular}


contain more irregular particles than a finer grained rockfill.

A comparison of the true sphericity and the corresponding 2D sphericity showed that 2D analysis would underestimate particle sphericity. Furthermore, by using the equivalent diameter instead of the geometrical average in the transforming equation, the CSD by surface area as well as by number can be successfully simulated. The modified approach takes into account the size and shape of particles and therefore allows a better representation of the CSD of coarse granular aggregates.

Further investigations need to be conducted to evaluate how a slight difference in particle shape and size of ballast would affect the physical and mechanical response of railroad ballast with different PSDs.

\section{REFERENCES}

Altuhafi, F. \& Coop, M. (2011). Changes to particle characteristics associated with the compression of sands. Géotechnique 61, No. 6, 459-471.

Altuhafi, F., O’Sullivan, C. \& Cavarretta, I. (2013). Analysis of an image-based method to quantify the size and shape of sand particles. ASCE J. Geotech. Geoenviron. Engng 139, No. 8, 1290-1307.

Anderson, W. F. \& Fair, P. (2008). Behavior of railroad ballast under monotonic and cyclic loading. ASCE J. Geotech. Geoenviron. Engng 134, No. 3, 316-327.

ASTM (2006). ASTM C136-06: Standard test method for sieve analysis of fine and coarse aggregates. ASTM International, West Conshohocken, PA, USA.

Blott, S. J. \& Pye, K. (2008). Particle shape: a review and new methods of characterization and classification. Sedimentology 55, No. 1, 31-63.

Cavarretta, I., Coop, M. \& O'Sullivan, C. (2010). The influence of particle characteristics on the behaviour of coarse grained soils. Géotechnique 60, No. 6, 413-423.

Cho, G., Dodds, J. \& Santamarina, J. (2006). Particle shape effects on packing density, stiffness, and strength: natural and crushed sands. ASCE J. Geotech. Geoenviron. Engng 132, No. 5, 591-602.

Cunningham, C. N., Evans, T. M. \& Tayebali, A. A. (2013). Gradation effects on the mechanical response of crushed stone aggregate. Int. J. Pave. Engng 14, No. 3, 231-241.

Einav, I. (2007). Breakage mechanics-part I: theory. J. Mech. Phys. Solids 55, No. 6, 1274-1297.

Fernlund, J. M. R. (1998). The effect of particle form on sieve analysis: a test by image analysis. Engng Geol. 50, No. 1, 111-124.

Fonseca, J., O'Sullivan, C., Coop, M. R. et al. (2012). Noninvasive characterization of particle morphology of natural sands. Soils and Found. 52, No. 4, 712-722.

Humes, C. (1996). A new approach to compute the void-size distribution curves of protective filters. Proc. Geofilters '96,
Comptes Rendus (Lafleur, J. \& Rollin, A. (eds)). Montreal: Bitech Publications, pp. 57-66.

Indraratna, B., Raut, A. K. \& Khabbaz, H. (2007). Constrictionbased retention criterion for granular filter design. ASCE J. Geotech. Geoenviron. Engng 133, No. 3, 266-276.

Krumbein, W. C. (1941). Measurement and geological significance of shape and roundness of sedimentary particles. J. Sediment. Res. 11, No. 2, 64-72.

Lackenby, J., Indraratna, B., McDowell, G. et al. (2007). Effect of confining pressure on ballast degradation and deformation under cyclic triaxial loading. Géotechnique 57, No. 6, 527-536.

Lee, J. R. J., Smith, M. L. \& Smith, L. N. (2007). A new approach to the three-dimensional quantification of angularity using image analysis of the size and form of coarse aggregates. Engng Geol. 91, No. 2, 254-264.

Le Pen, L., Powrie, W., Zervos, A. et al. (2013). Dependence of shape on particle size for a crushed rock railway ballast. Gran. Matter 15, No. 6, 849-861.

Locke, M., Indraratna, B. \& Adikari, G. (2001). Time-dependent particle transport through granular filters. ASCE J. Geotech. Geoenviron. Engng 127, No. 6, 521-529.

Moaveni, M., Qian, Y. H., Mishra, D. et al. (2014). Investigation of ballast degradation and fouling trends using image analysis. Proc. 2nd Int. Conf. on Railway Technology: Research, Development and Maintenance (Pombo, J. (ed.)). Stirlingshire, UK: Civil-Comp Press, Paper 123, http://dx.doi.org/10.4203/ccp.104.123.

Muszynski, M. R. \& Vitton, S. J. (2012). Particle shape estimates of uniform sands: visual and automated methods comparison. J. Mater. Civ. Engng 24, No. 2, 194-206.

O'Sullivan, C., Bray, J. D. \& Riemer, M. F. (2002). Influence of particle shape and surface friction variability on response of rodshaped particulate media. J. Engng Mech. 128, No. 11, 1182-1192.

Rousé, P. C., Fannin, R. J. \& Shuttle, D. A. (2008). Influence of roundness on the void ratio and strength of uniform sand. Géotechnique 58, No. 3, 227-231.

Shin, H. \& Santamarina, J. (2012). Role of particle angularity on the mechanical behavior of granular mixtures. ASCE J. Geotech. Geoenviron. Engng 139, No. 2, 353-355.

Silveira, A., Peixoto, D. L. T. \& Nogueira, J. B. (1975). On void size distribution of granular materials. Proc. 5th Pan-American Conference on Soil Mechanics and Foundations Engineering, Buenos Aires, pp. 161-176.

Standards Australia (1999). AS 1141.15: Methods for sampling and testing aggregates - flakiness index. Sydney: Standards Australia.

Thom, N. H. \& Brown, S. F. (1988). The effect of grading and density on the mechanical properties of a crushed dolomitic limestone. Proc. 14th Australian Road Research Board (ARRB) Conf., Canberra 14, 94-100.

Trani, L. \& Indraratna, B. (2010). The use of particle size distribution by surface area method in predicting the saturated hydraulic conductivity of graded granular soils. Géotechnique 60, No. 12, 957-962.

Wadell, H. (1935). Volume, shape, and roundness of quartz particles. J. Geology 43, No. 3, 250-280. 